\title{
Anchor, Spacer, and Ligand-modified engineered exosomes for trackable targeted therapy
}

Changsun Kang, ${ }^{\dagger}$ Patrick Han,,${ }^{\ddagger}$ Jung S. Lee, ${ }^{\ddagger}$ Dongwon Lee, ${ }^{\prime}$ and Dongin Kim ${ }^{*} \uparrow$

\section{AUTHOR ADDRESS}

†Department of Pharmaceutical Sciences, College of Pharmacy, University of Oklahoma Health

Sciences Center, Oklahoma City, OK, 73117

Department of Biomedical Engineering, Yale University, New Haven, CT, 06511

"Department of Polymer-Nano Science and Technology, Chonbuk National University, Jeonju, South Korea, 54896

*Address correspondence to Dongin-Kim@ouhsc.edu 

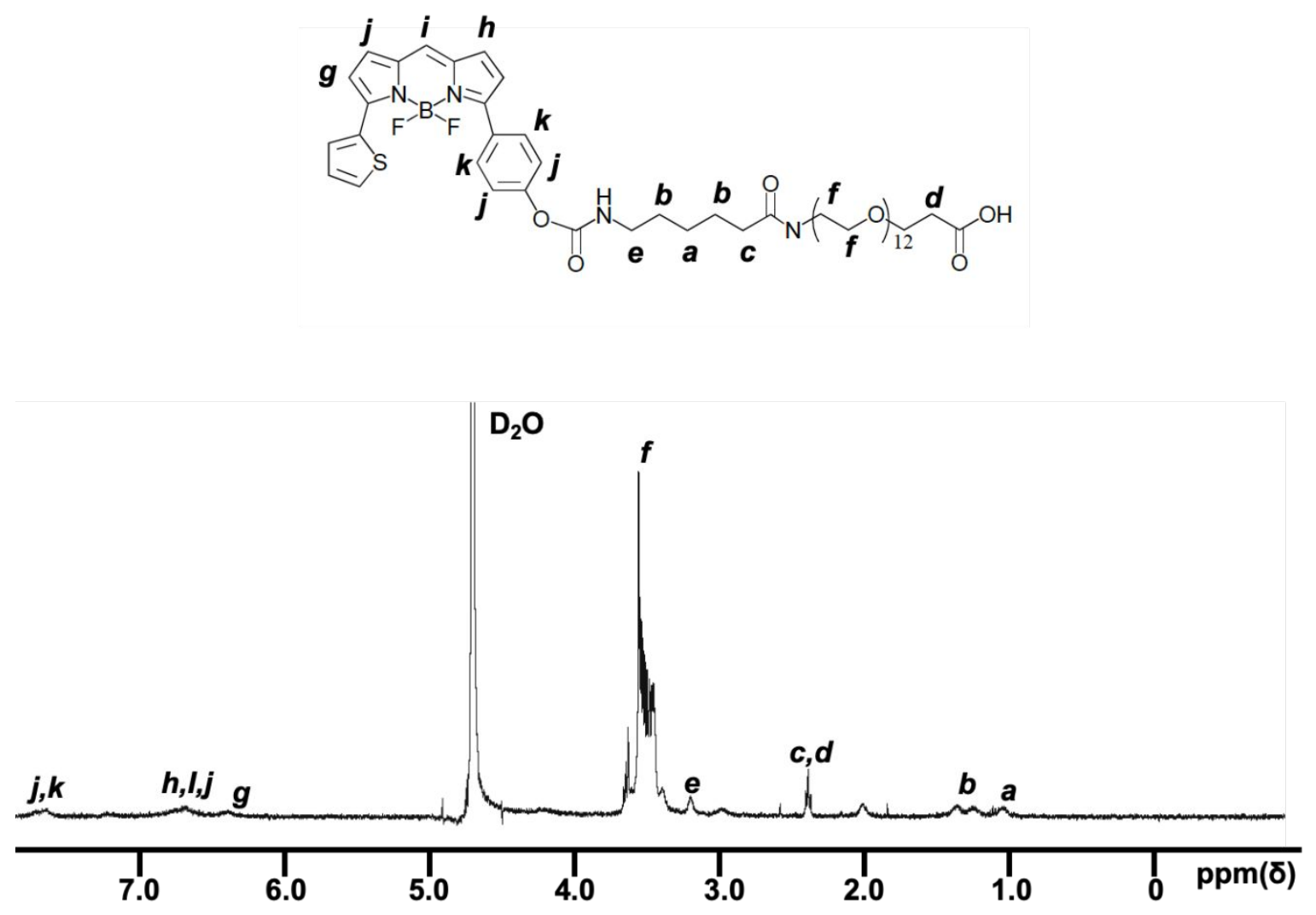

Figure S1. ${ }^{1} \mathrm{H}$ NMR spectrum of compound 1 recorded in $\mathrm{D}_{2} \mathrm{O}$. 


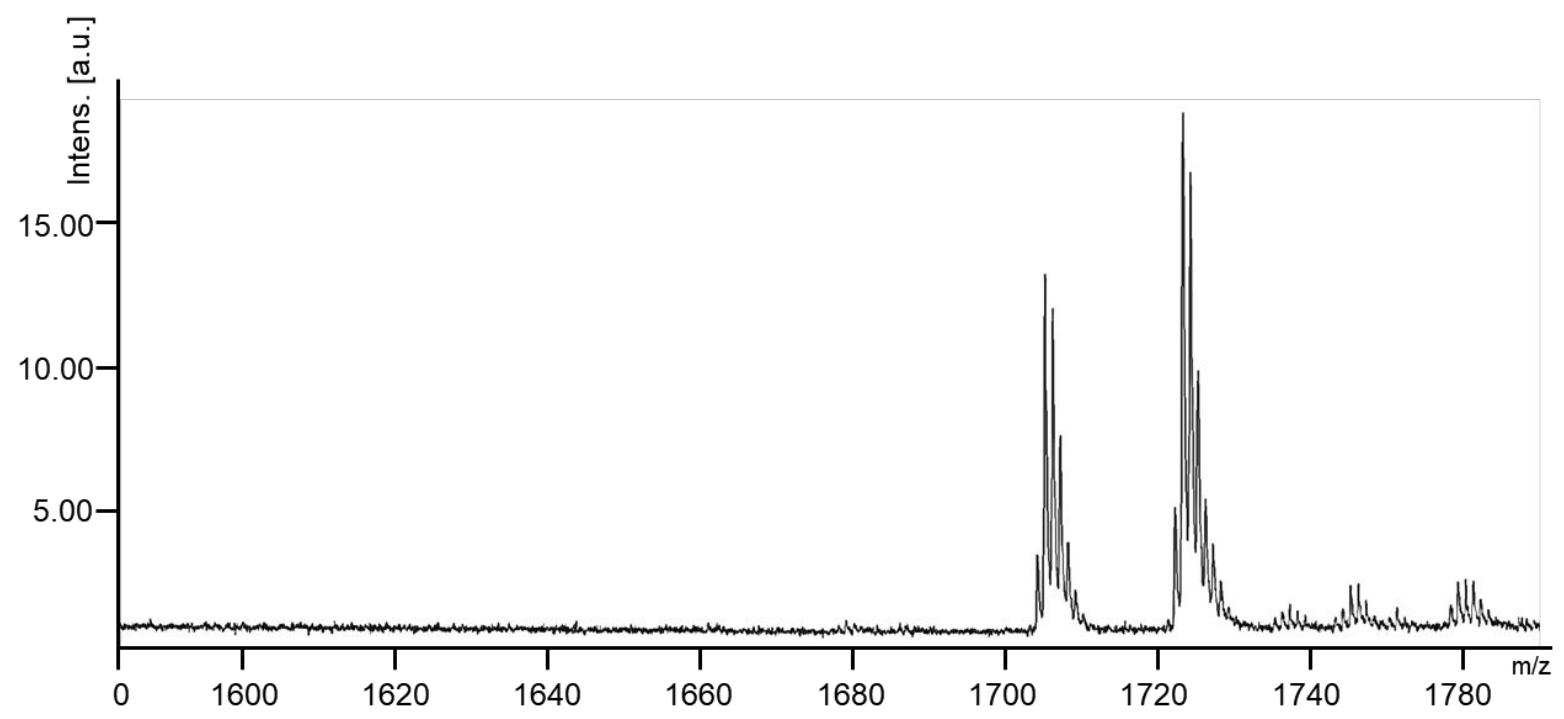

Figure S2. Determination of molecular weight distribution of ASL through MALDI-TOF analysis. 


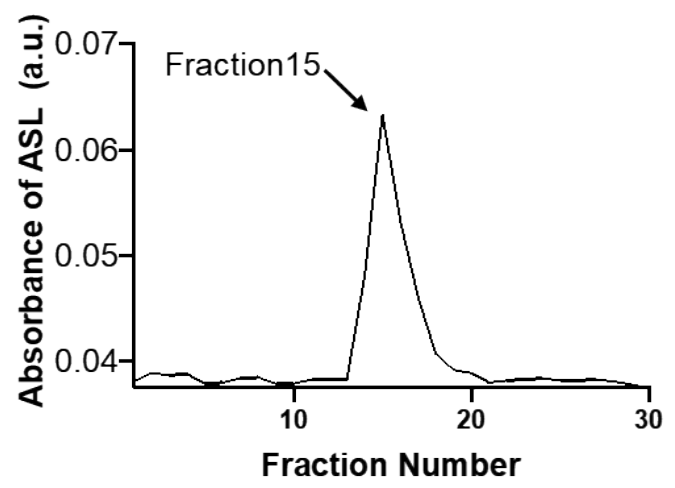

Figure S3. Elution profile of ASL using a Sephacryl S100 column. 
(a)

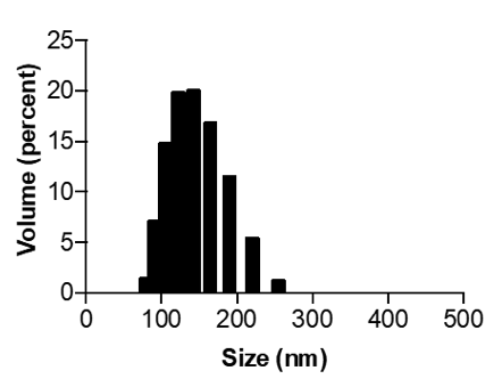

(b)

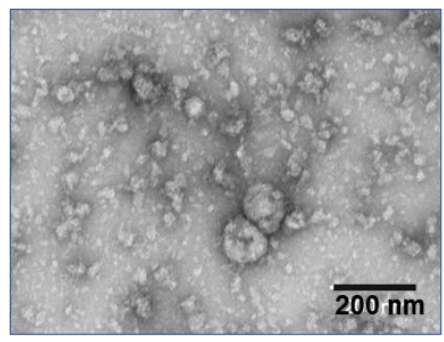

(c)

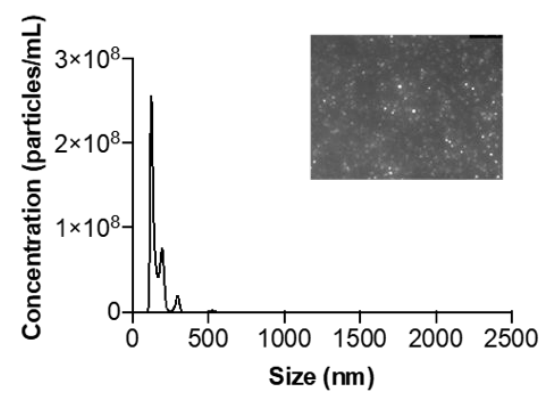

Figure S4. Characterization of free exosomes. (a) Size distribution determined by dynamic light scattering. (b) Representative transmission electron micrograph. (c) Size distribution profile generated by nanoparticle tracking analysis. 
(a)

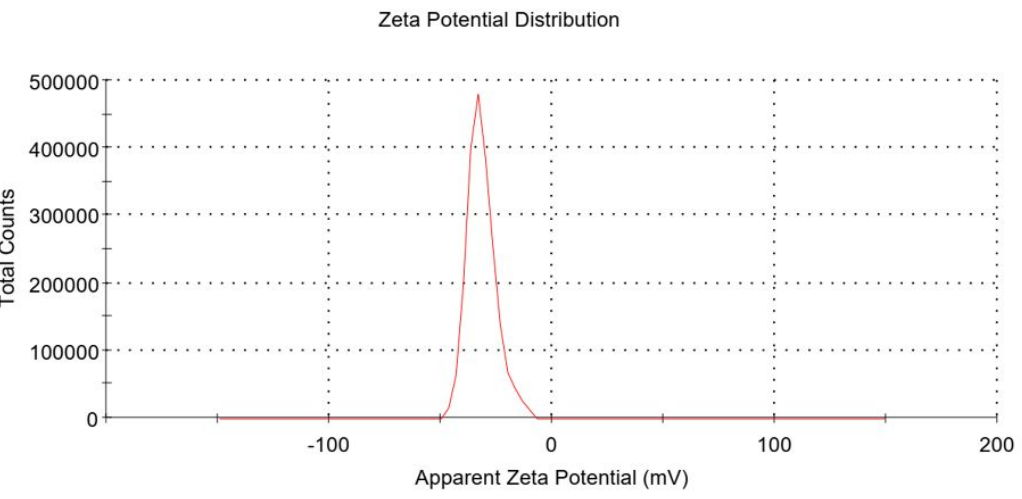

(b)

Zeta Potential Distribution

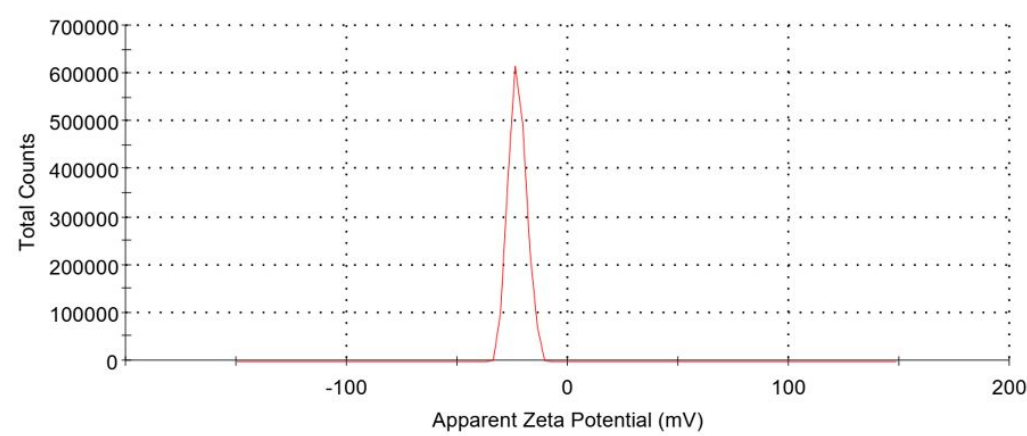

Figure S5. Zeta potential distribution of (a) exosomes and (b) dAEx. 


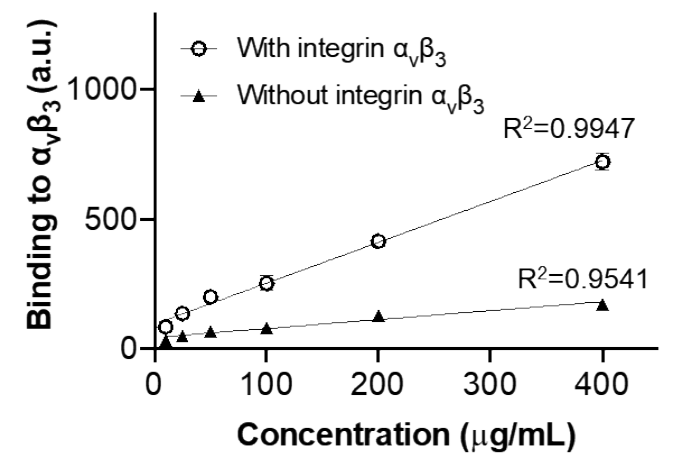

Figure S6. Integrin $\alpha_{v} \beta_{3}$-dependent or non-specific binding of ASL. 


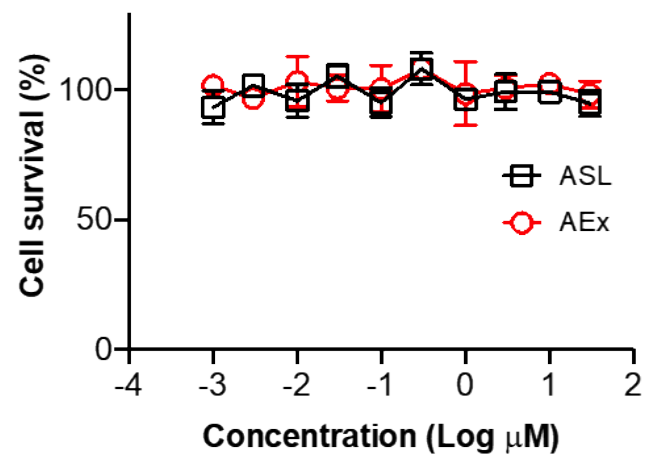

Figure S7. Cytotoxicity of ASL and AEx against B16F10 cells. 


$$
\begin{array}{r}
\text { Integrin } \alpha_{v} \\
\text { Integrin } \beta_{3} \\
\beta \text {-actin }
\end{array}
$$

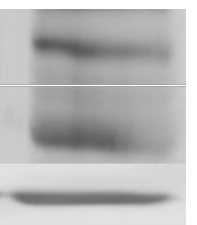

Figure S8. Expression of integrin $\alpha_{\vee} \beta_{3}$ of b16F 10 cells. 
(a)

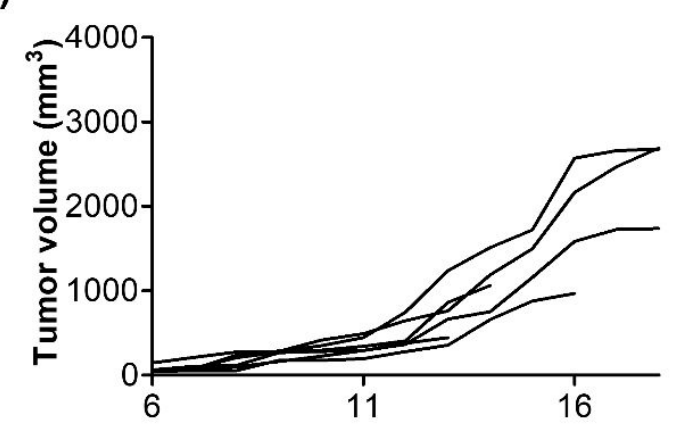

(c)

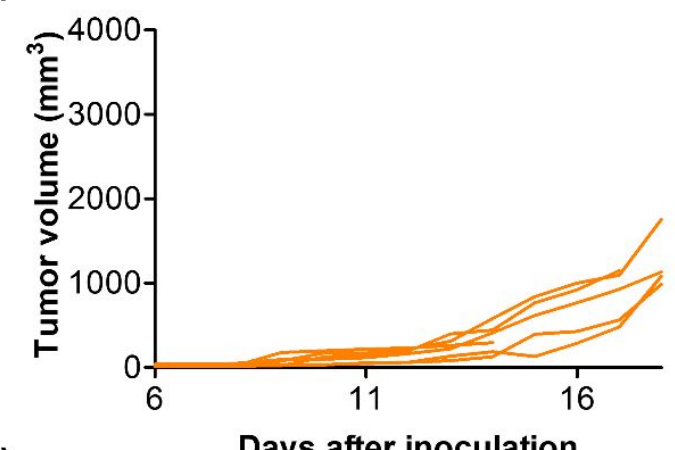

(e)

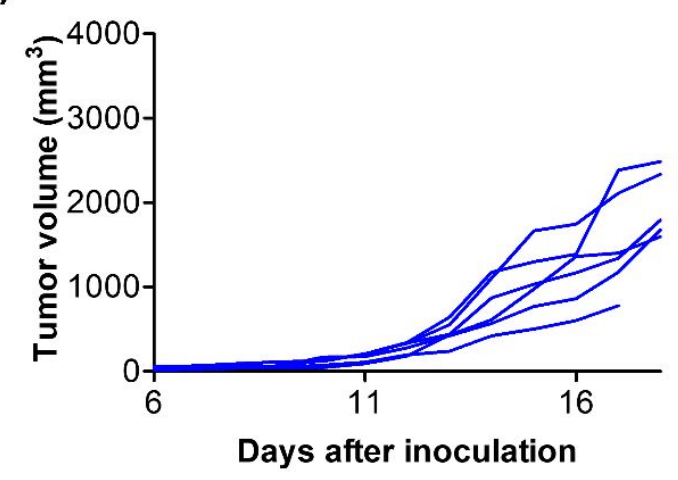

(b)

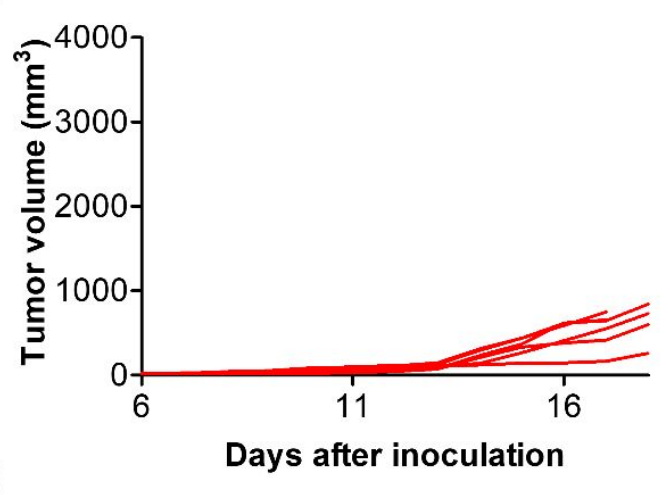

(d)

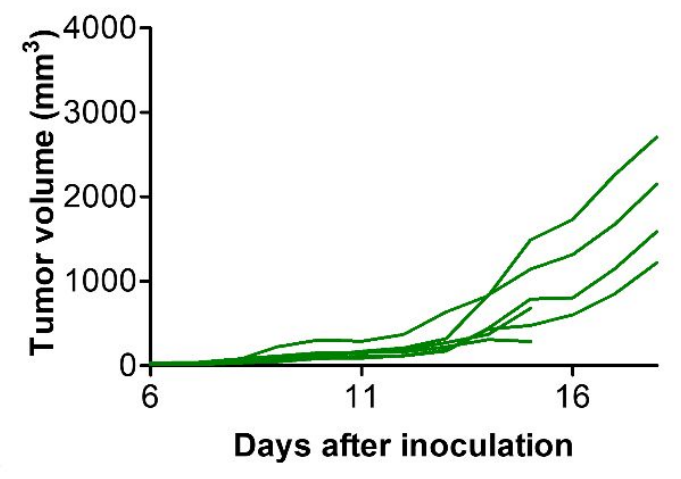

(f)

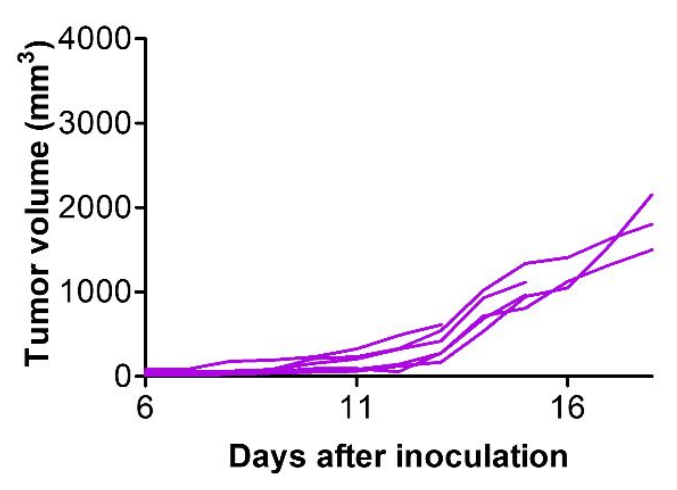

Figure S9. The individual tumor growth was observed after treatment. (a) Untreated, (b) dAEx, (c) dEx, (d) DOX, (e), ASL, and (f) Ex. 

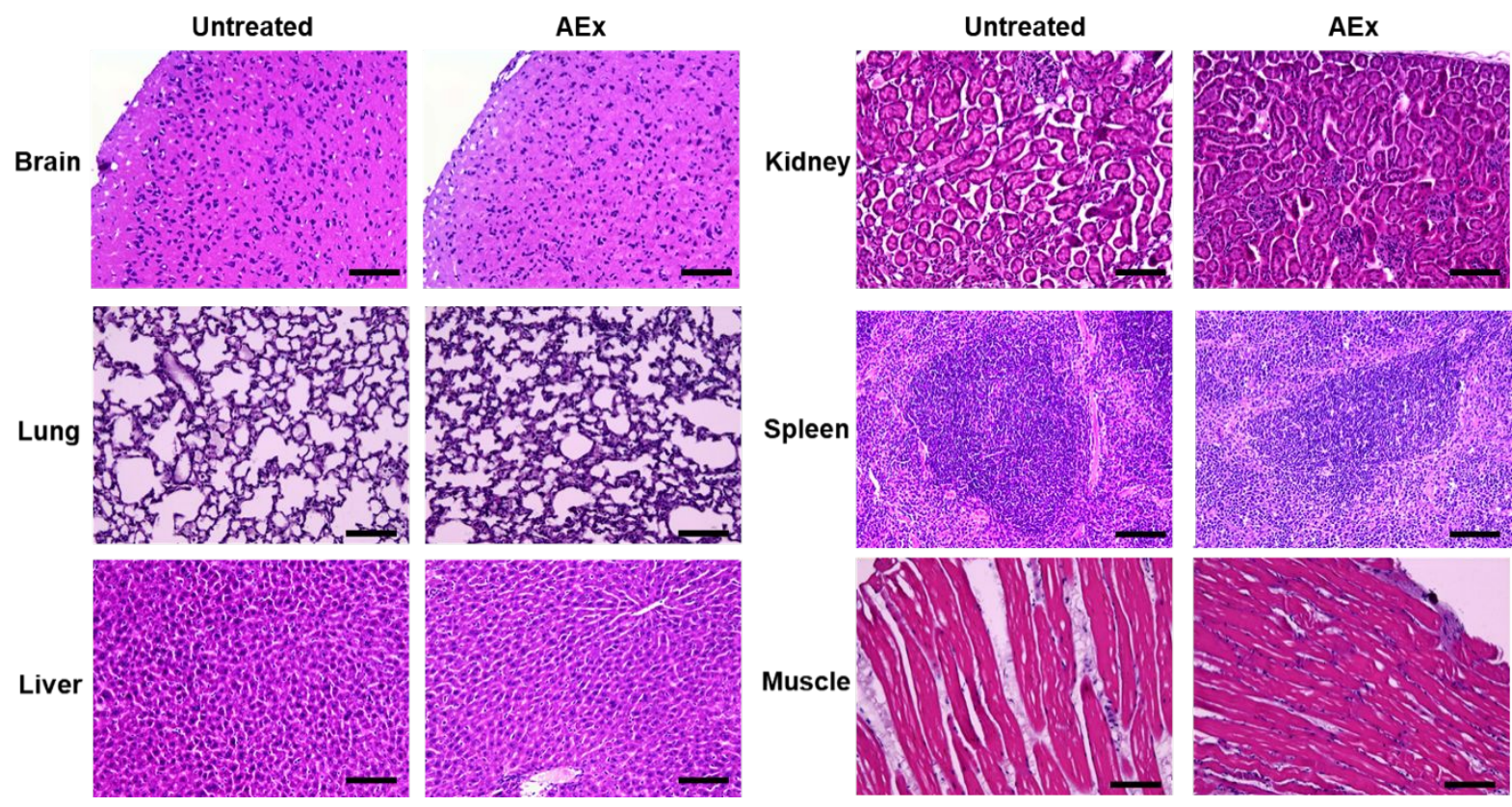

Figure S10. In vivo toxicity of AEx using H\&E-stained organs from AEx-treated mice (X200).

Scale bar represent to $100 \mu \mathrm{m}$. 